\title{
Investigation of the plasma levels of CCL-17 and CCL-25 and their receptor gene expression in rheumatoid arthritis patients
}

\author{
Samimi $Z^{1}$, Kardideh $B^{2}$, Mohammadi-Farani $A^{3,4}$, Darabinejad $M^{5}$, Taghadosi $M^{6}$ \\ 1. MSc of Immunology, Immunology Department, Faculty of Medicine, Kermanshah University of Medical Sciences, \\ Kermanshah, Iran. ORCID ID: 0000-0003-0333-8683 \\ 2. MSc of Immunology, Immunology Department, Faculty of Medicine, Kermanshah University of Medical Sciences, \\ Kermanshah, Iran. \\ 3. Associate Professor of Pharmacology, Pharmaceutical Sciences Research Center, School of Pharmacy, Kermanshah \\ University of Medical Sciences, Kermanshah, Iran. \\ 4. Associate Professor of Pharmacology, Department of Pharmacology, Toxicology and Medical Services, Kermanshah \\ University of Medical Sciences, Kermanshah, Iran. \\ 5. Student of Pharmacy, School of Pharmacy, Kermanshah University of Medical Sciences, Kermanshah, Iran. \\ 6. Assistant Professor of Immunology, Department of Immunology, Kermanshah University of Medical Sciences, \\ Kermanshah, Iran (Corresponding Author), Tel:+98-8334274623, Email:mtaghad@gmail.com, ORCID ID: 0000-0002-3516- \\ 0130
}

\begin{abstract}
Background and Aim: Rheumatoid arthritis (RA) is an autoimmune inflammatory disease of unknown etiology. The chemokines and their related receptors have a pivotal role in migration and homing of leukocyte involved in the pathogenesis of RA. The goal of this study was to measure the plasma levels of CCL-17 and CCL-25 and their receptors gene (CCR4 and CCR9) expression in rheumatoid arthritis patients.

Materials and Methods: 30 untreated newly diagnosed and 30 under treatment RA patients with disease modifying anti-rheumatic drugs (DMARDs) as well as 30 healthy subjects participated in this study. We assessed the gene expression of CCR 4 and CCR9 by the realtime PCR method, and measured plasma levels of CCL25 and CCL17 by enzyme-linked immunosorbent assay (ELISA).

Results: Comparison between control group and newly diagnosed rheumatoid arthritis patients showed significantly lower expression of CCR4 and CCR9 ( $\mathrm{P}=0.047, \mathrm{P}=0.049$ respectively) in the latter group. In addition, the plasma level of CCL-25 was significantly lower in both newly diagnosed and under treatment RA patients compared to that in the healthy subjects $(\mathrm{P}=0.017, \mathrm{P}=0.030$ respectively).

Conclusion: The altered expression of chemokines and their related receptors, especially those involved in the leukocyte migration to the mucosa of the gastrointestinal tract may be associated with the pathogenesis of RA.
\end{abstract}

Keywords: Rheumatoid arthritis, Chemokines, Chemokine receptors, DMARD

Received: Feb 3,2019 Accepted: June 30, 2019

\footnotetext{
How to cite the article: Samimi Z, Kardideh B, Mohammadi-Farani A, Darabinejad M, Taghadosi M. Investigation of the plasma levels of CCL-17 and CCL-25 and their receptor gene expression in rheumatoid arthritis patients. SJKU 2019;24(3):121-133.
} 


\title{
بررسى ميزان سطح بلاسمايى كموكاينهاى CCL17 و CCL25 و ميزان بيان ثن تيرندههاى آنها در بيماران آرتريت روماين
}

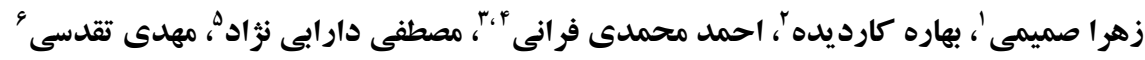

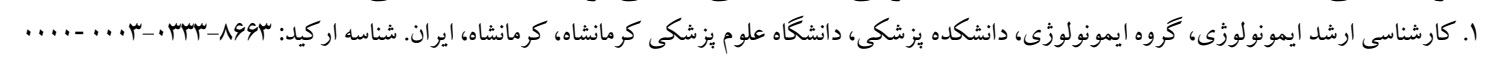

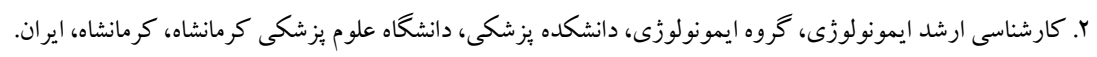

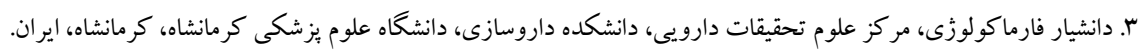

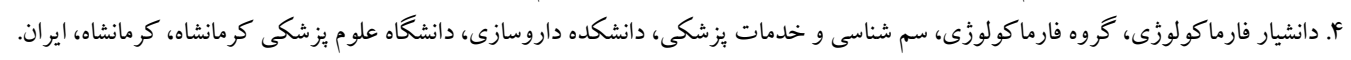

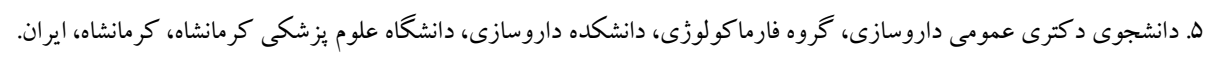

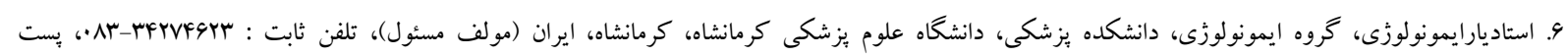

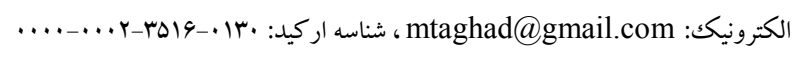

جִكيده

زمينه و هدف: آرتريت روماتوئيد (RA) يكك بيمارى خود ايمن التهابى با علت ناشناخته است.كمو كاينها و كيرندههاى آنها

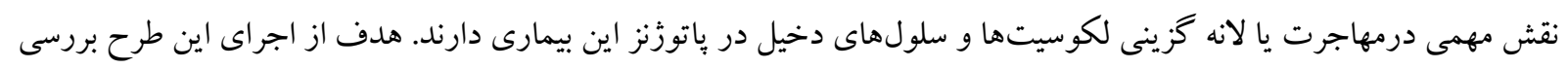

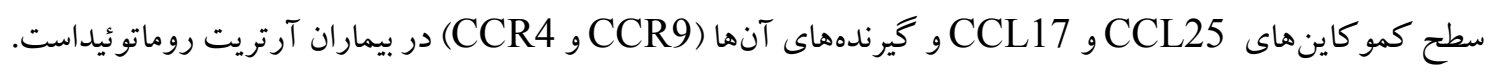

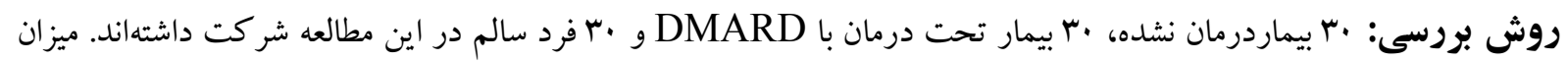

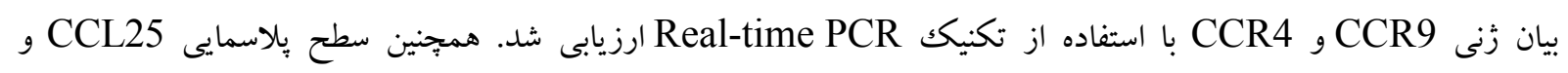
CCL17 با كمكك روش الايزا بدست آمد. يافته ها:بيان هر دو زن CCR9 CCR4 در گروه بيمار تازه تشخيص داده شده نسبت به گروه كنترل به صورت معنادارى كمتر

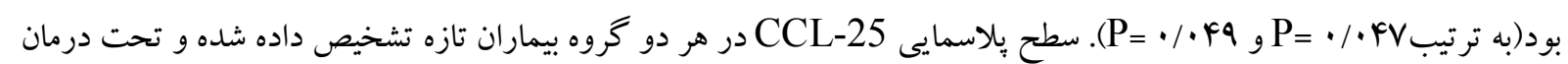

$$
\text { به صورت معنادار كمتر از خروه كنترل بود (به ترتيب P }
$$

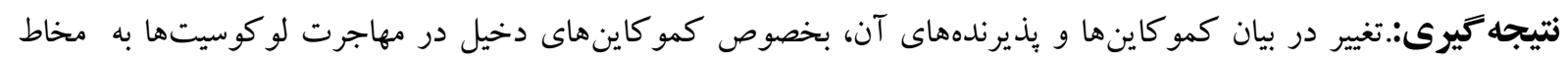

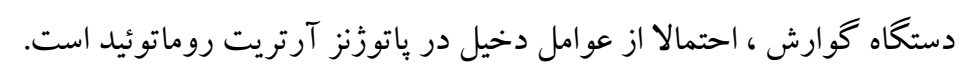

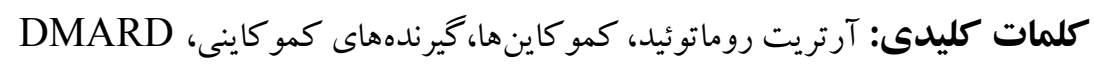

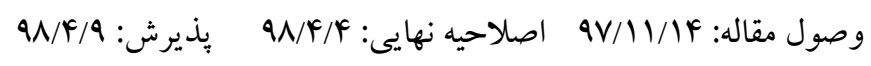




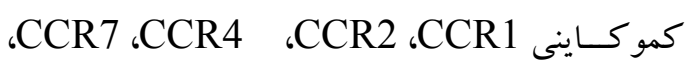
CCR5 و CXCR3

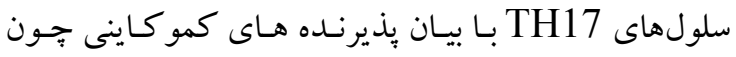

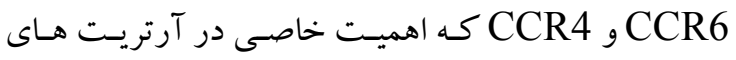

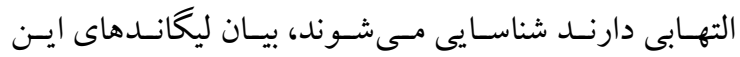

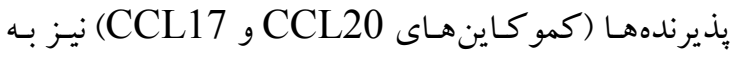
مقدار زيادى در مفاصل ملتهب بـالا مسرود كـه ايـن تقابـل

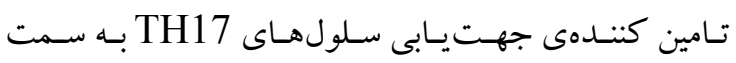

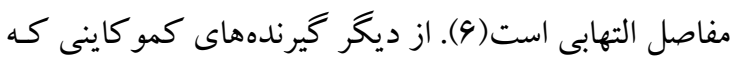

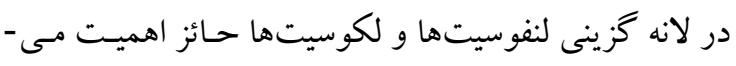

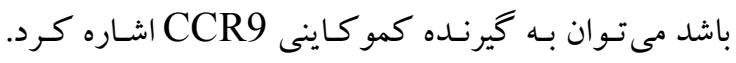
كيرنده كمو كاينى CCR9 براى اولين بار روى تيموسيت-

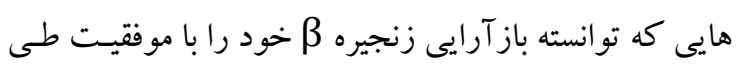

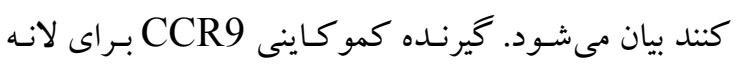

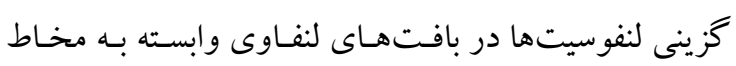

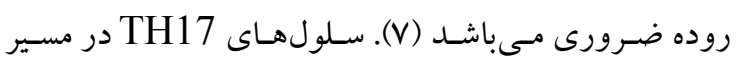
Aيزيولوزيكك باز كردش خود به روده تحت تاثير ويتـامين

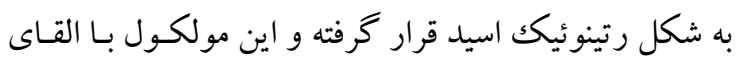

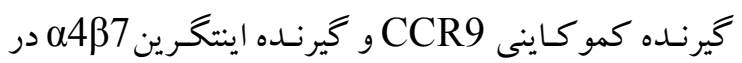

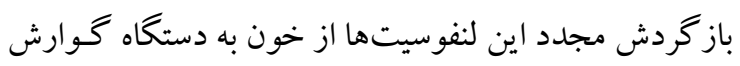

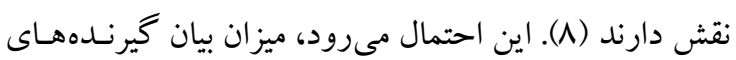
كموكسـينى CCR9 و CCR4 و ليگانسدهاى آنهـ CCL25 CCL17 لنفوسيتها نقش دارند در بيماران مبتلا به ارتريت روماتوئيد در سطح لكوسيتها و لنفوسيت ها دستخوش تغييـر شـود و

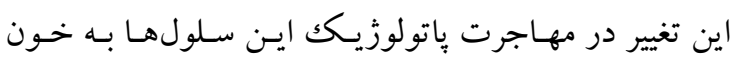

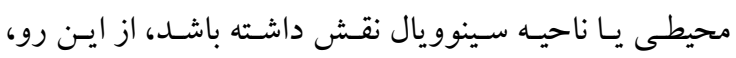

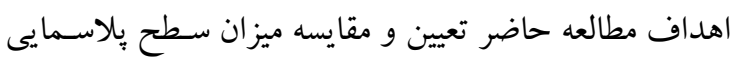

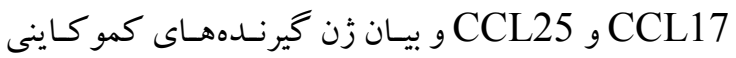

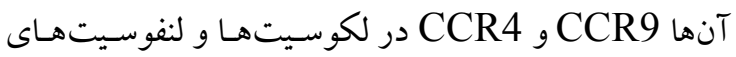
خون محيطى بيمـاران تـازه تشخيص داده شــه و همجنـين بيماران تحت درمان با داروهاى ضد روماتوئيد تغيـر دهنده

\section{مقدمه}

آرتريـت روماتوئيــ (RA) يـك بيمـارى التهابى مـزمن بـا

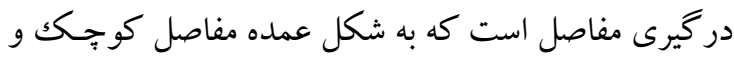
قرينه دست و يا را دركير مى كنـــ ايـن بيمـارى شـايع ترين

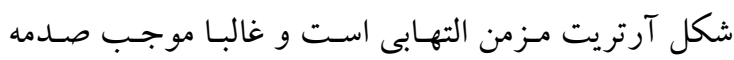
مفصلى و ناتوانى بدنى مى شود (1). التهاب مشـاهده شـده در

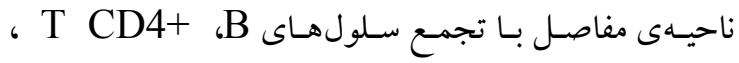

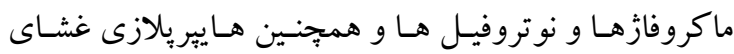

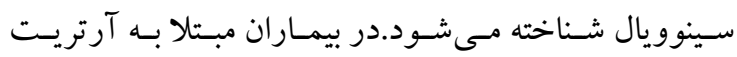

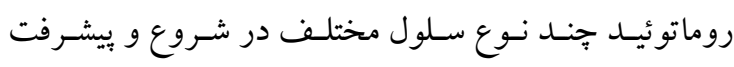
بيمارى نقش دارند كه از آن جمله مى تـوان بـه ماكروفازهــا، مونوسيت ها، سـلولهـاى دنـدرتيكك و سـلولهـاى T T اشـاره

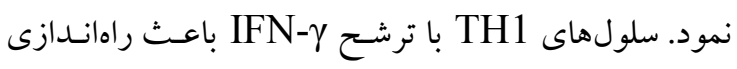

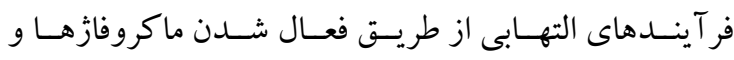

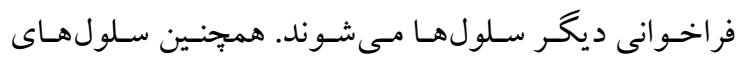

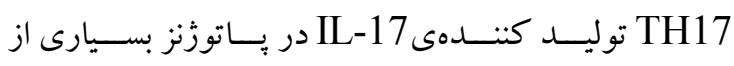

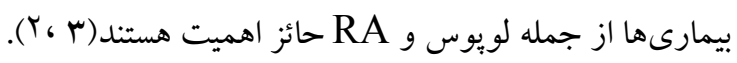

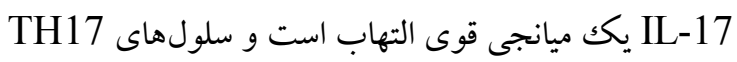
در خون محيطى و مايع مفصلى بيماران RA يافت مى شـوند

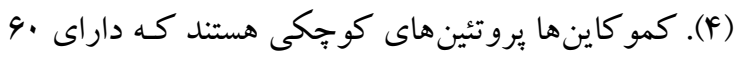

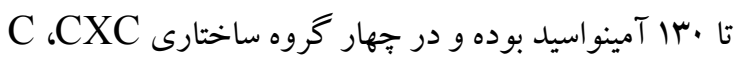

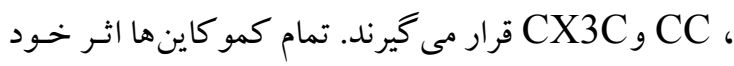

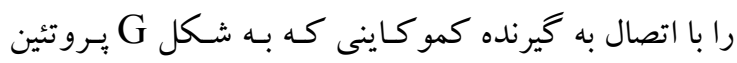

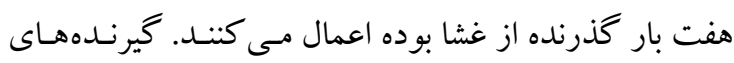

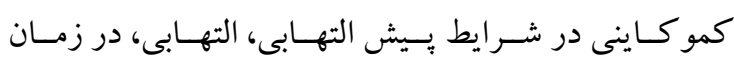

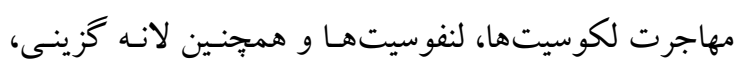

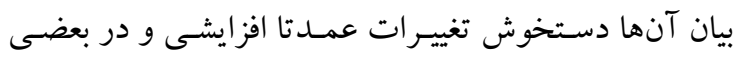
مـوارد كاهشـى مسىشـوند. در بيمـارى آرتريـت روماتوئيـد

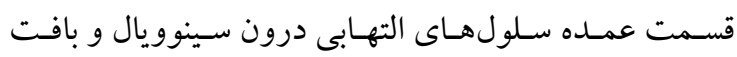
سينوويوم تجمع بيدا مى كنتـد و بـا بيـان كيرنسـد كمو كـاينى شرايط التهابى را تشديد مى كنند. در بافت سينوويوم بيماران

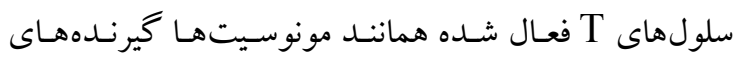


عرا ابررسى ميزان سطح بِلاسهاِيى...

بعدى سطح كمو كاينها در ·V- درجه سانتى گر اد نگهدارى روند بيمارى (DMARD) مبتلا به آرتريت روماتوئيد مى -

سـنجش ســطح يلاسـمايى CCL17 و CCL25 سـطحح بلاسـمايى CCL17 و CCL25 بـا اسـتفاده از تكنيـك

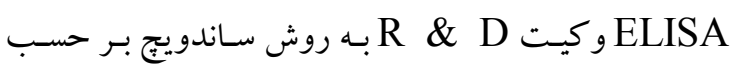

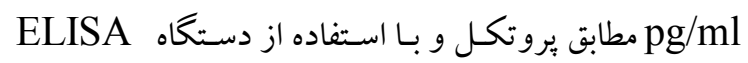
تعيين شد.

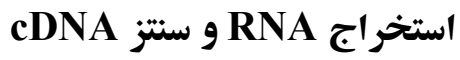

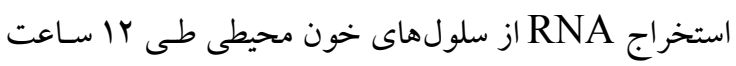

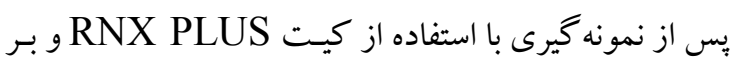

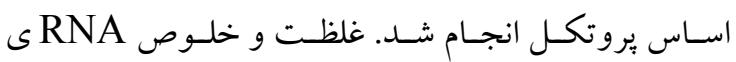

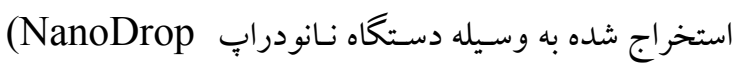
2000UV-Vis Spectrophotometer / Thermo RNA) \% و الكتروفروز زل آكارز Scientific, USA) با كيفيت مناسب دو بانــ rRNA شدت حدود r دارد) مورد بررسى قرار گرفـت. بـراى سـنتز از كيت Roche استفاده شد و نمونهها براى انجام مر احل بعدى در دماى •V- نخه دارى شدند.

بروسى بيان خن CCR4 و CCR9

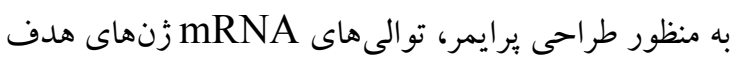

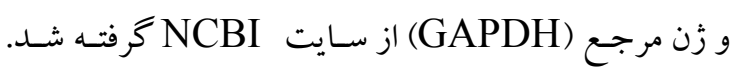

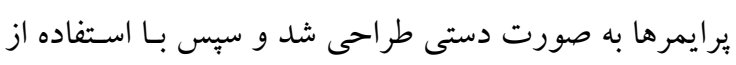

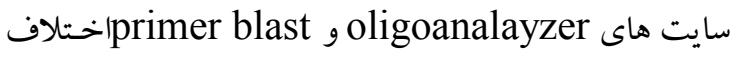
دمـاى بر ايمرهـا، عـدم تشـكيل برايمـر دايمـر و اتصـال غيـر

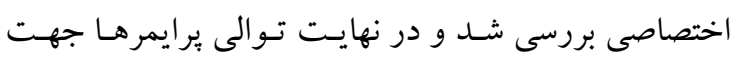

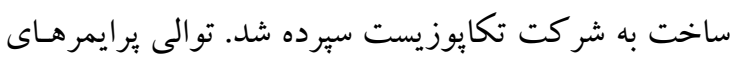

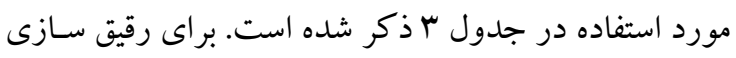

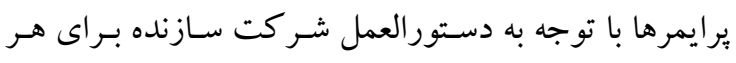

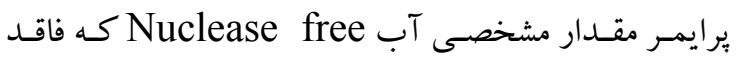

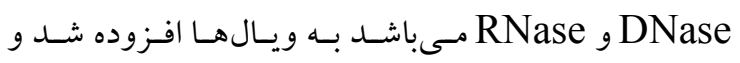

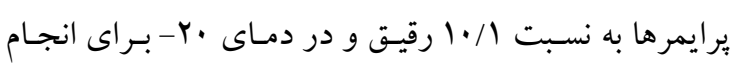

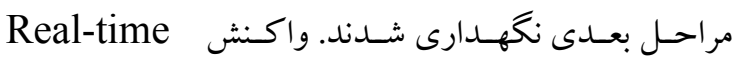

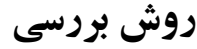 جمعيت مورد مطالعه}

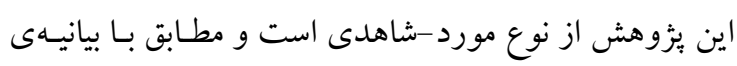

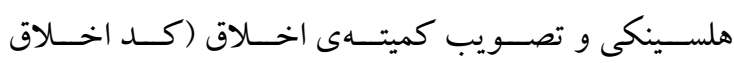

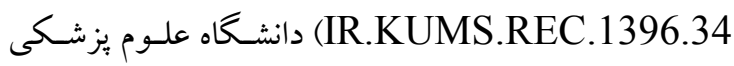
كرمانشاه انجام شد. همه شر كت كنند گان رضايت آكاهانه

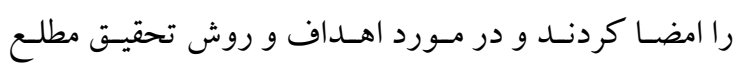

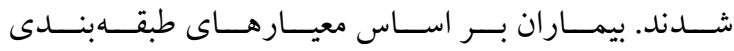
EULAR/ACR 2010

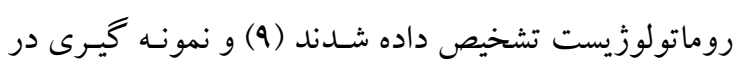

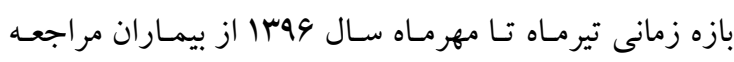

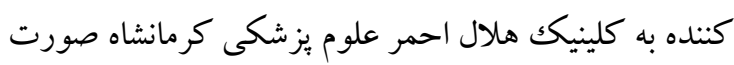

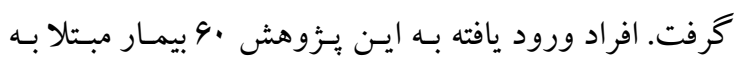
آرتريت روماتوئيد در دو گروه تازه تشخيص (بيمـارانى كه. دارو دريافت نكردند) و تحت درمان (بيماران تحت درمان بان

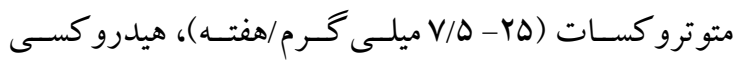

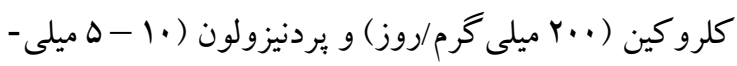

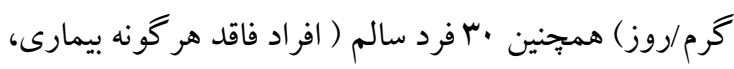

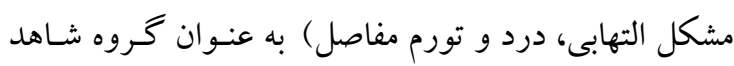

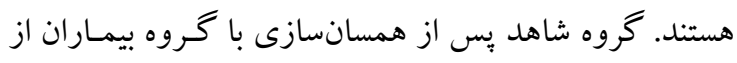

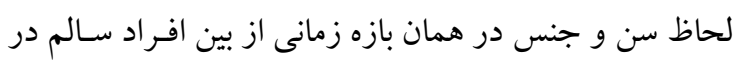

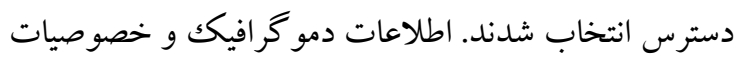

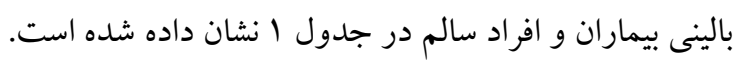

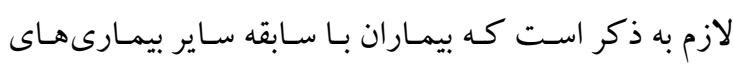
اتو ايميون، مفصلى، عفونت شديد، سـرطان و همجِنين زنـان باردار از مطالعه حذف شدند. جداسازى نمونه يُاسما

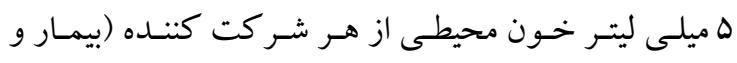

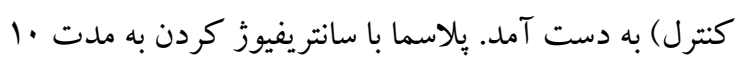

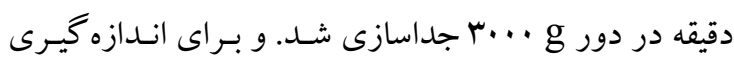


بزشك معالج و بررسى برونـده بزشكى بيمـار جمسع آورى

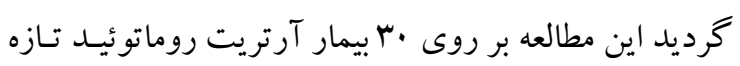

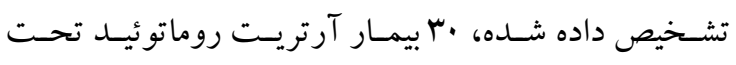

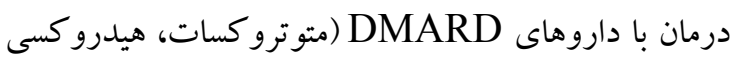

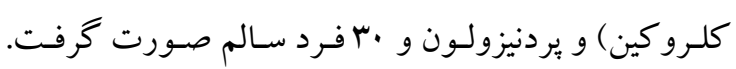

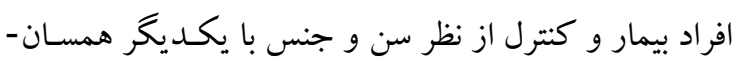

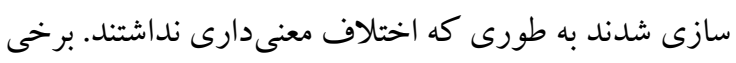

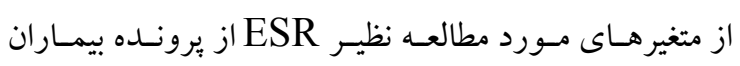

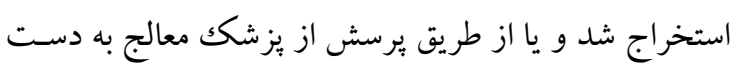

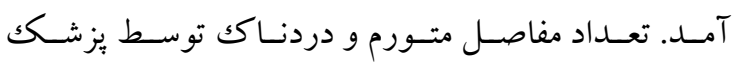
روماتولوزيست مورد بررسى قرار گرفت و بـر اسـاس آنهـا

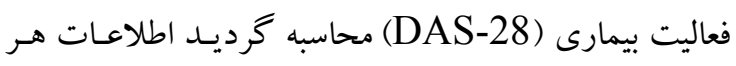
سه گروه در جدول انشان داده شده است.

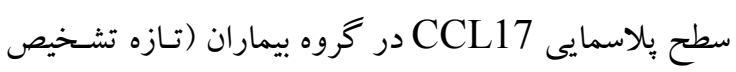

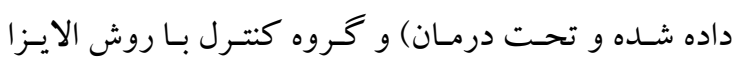

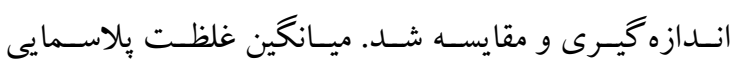
CCL17

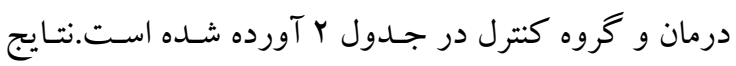

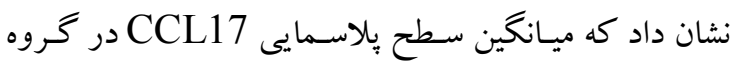

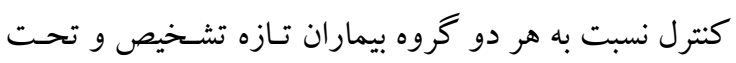
درمان كمتر بود اما ايـن تفـاوت بـه لحساظ آمـارى معنسدار

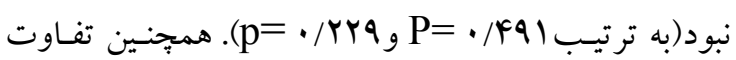
آمارى معنى دارى در دو گروه بيمار تازه تشخيص داده شده تردي

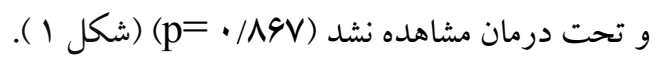

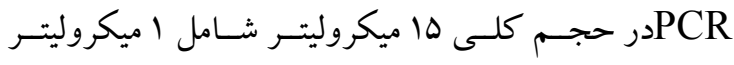

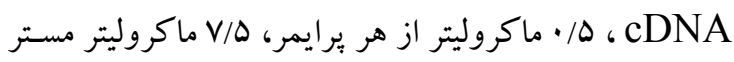

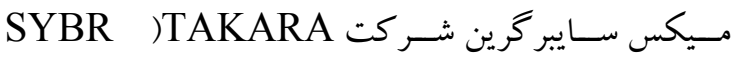
Green Master Mix: RNase H Plus SYBR و و ها هاكروليتر Premix Ex Taq II از دستخاه Roche Life Science LightCycler 96طبق برنامه ذكر شده در جدول ^ أنجام شد. تحليل آمارى تحليل آمـارى دادههـاى بلدست آمارى آمـده و رسـم نمودارهـا بـهـ

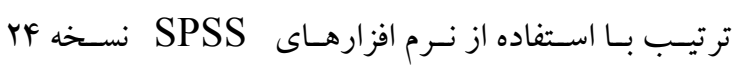
و صورت گرفت. براى مقايسه

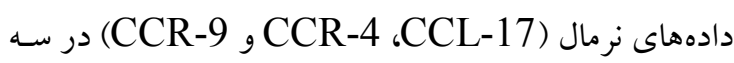
كروه از روش آمارى ANOVA (و براى مقايسـه ميـانگين

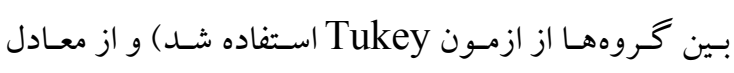
نايارامترى KrusKal Wallis ، ANOVA براى مقايسه دادههـاى غيرنرمـال (CCL-25) اسـتفاده شـد. محاسـبات دادهها بين دو گروه تحت درمان و تازه تشخيص داده شده با

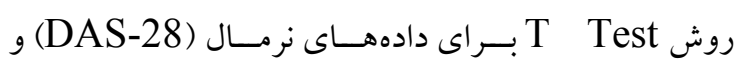
Mann-Whitney U

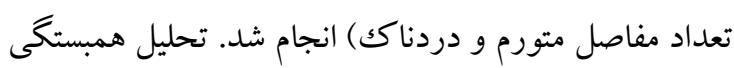

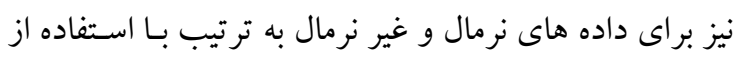

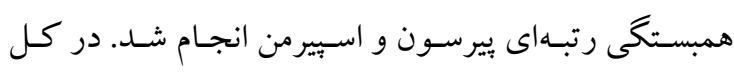

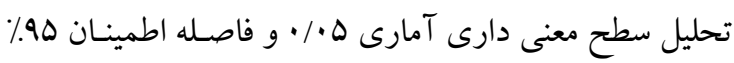

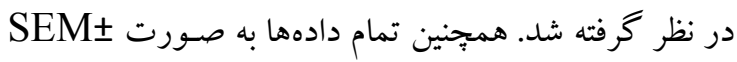
ذكر شده است.

\section{يافتهها}

اطلاعات دمو گر افيكك هر بيمار به صورت جداكانه از طريق

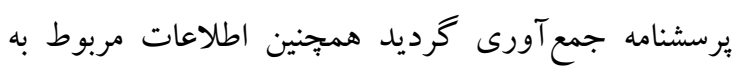

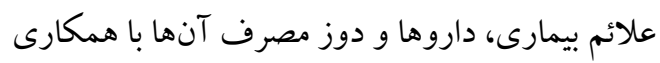




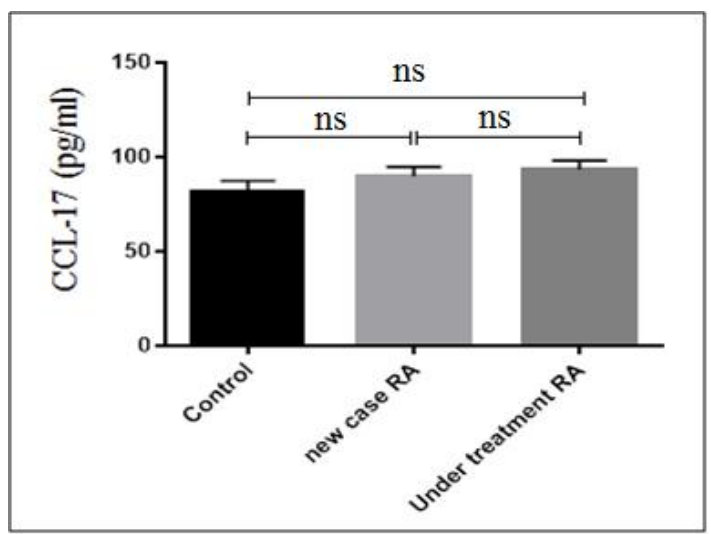

ns: not significant شكل 1: مقايسه ميانكين سطح بلاسمايى CCL17 در كروه بيماران RA گروه كترل،

تحت درمان بالاتر بود ( به ترتيـب p=

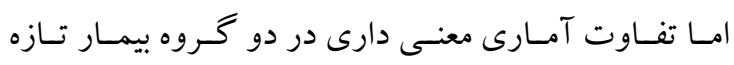

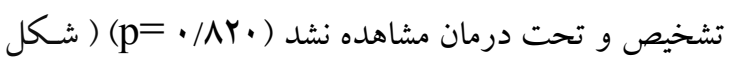

سطح يلاسمايى CCL25 در گروه بيماران (تازه تشـخيص

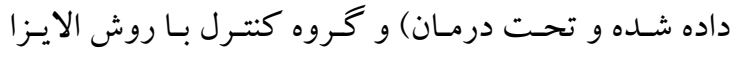

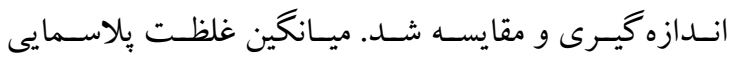

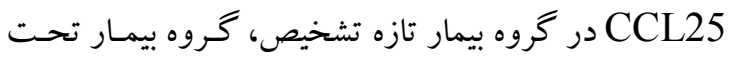

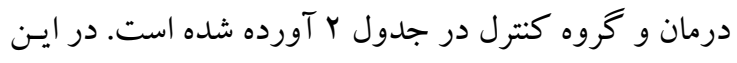

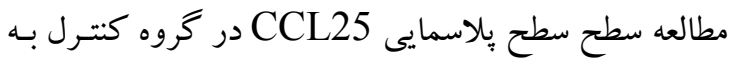

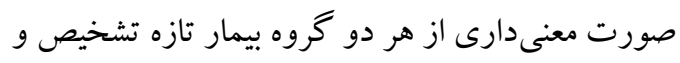

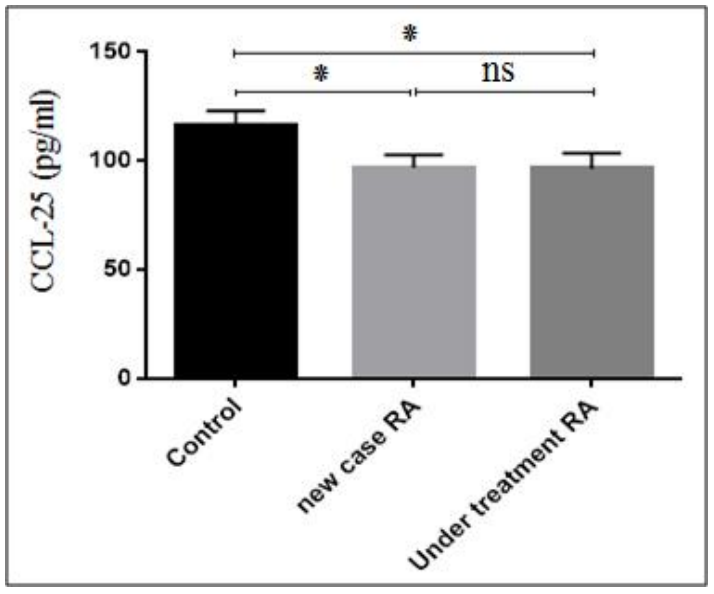

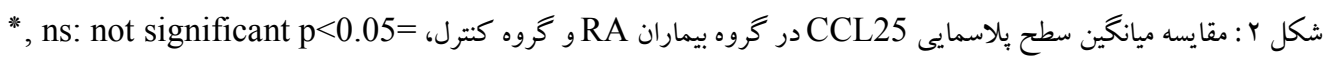


آناليز دادهها نشان داد كه بيـان زن CCR4 در گروه بيمـار

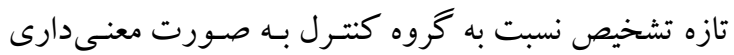
بيان نسبى هر كدام از زُنها نسبت به زُن مرجع بـا استفاده از

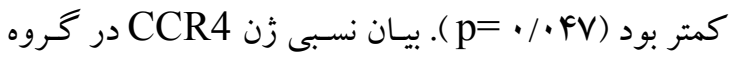
بيمار تازه تشخيص نسبت به گروه تحت درمان كمتر بود اما فرمول رياضى Pffafl، محاسبه شد ( (1). $\mathrm{R}=[$ (Etarget) $\Delta \mathrm{Ct}$ target (control - sample)/(ERef) $\Delta \mathrm{Ct} \operatorname{Ref}($ control - sample)] ايسن تفـاوت از نظـر آمـارى معنسىدار نبـود (p= ). pN ).

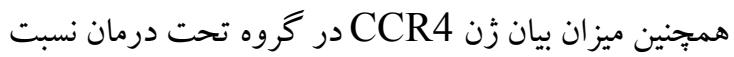

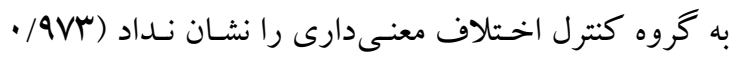
( شكل (r) (p= سـوح بيـان زنهـاى CCR4 و CCR9 در نمون بيماران و افراد سالم مورد تجزيه و تحليل قرار گَرفت نتـايج بدست آمده اختلاف معنىدارى بين بيـان mRNA هاى CCR4 و CCR9 در گروههاى مـورد مطالعه نشان

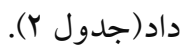

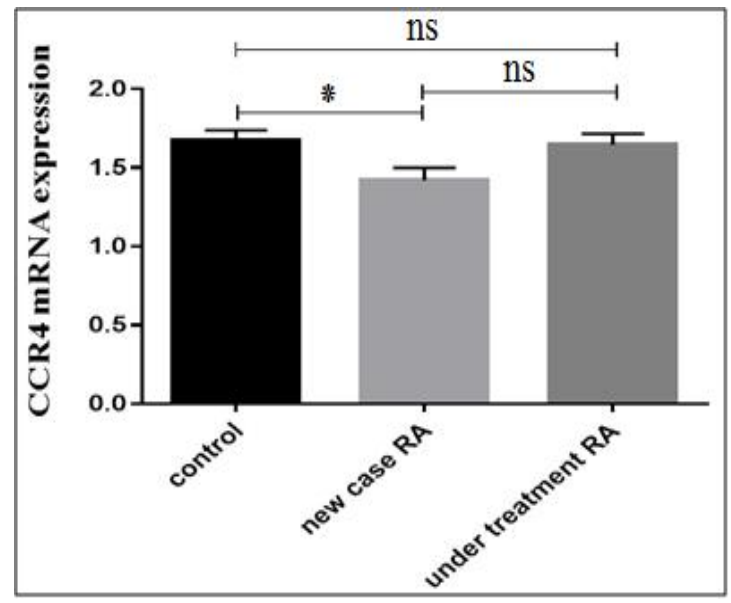

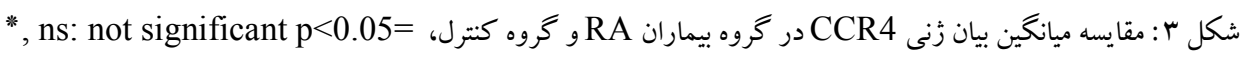

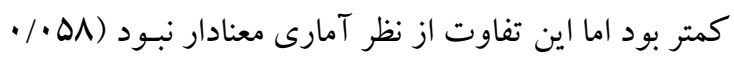

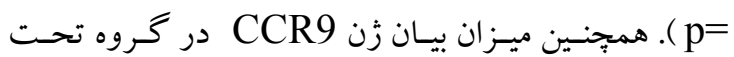

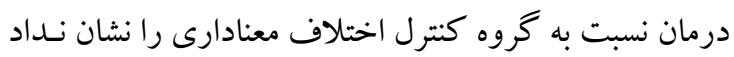

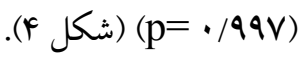

همبِنسين آنـاليز دادههـا نشـان داد كـه بيـان زن CCR9 در

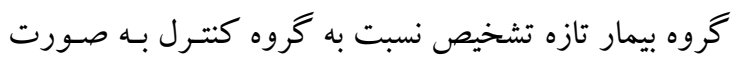

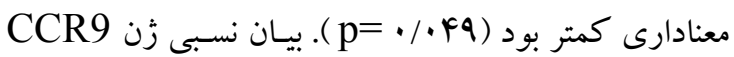
در گروه بيمار تازه تشخيص نسبت بـه گرووه تحـت درمـان 


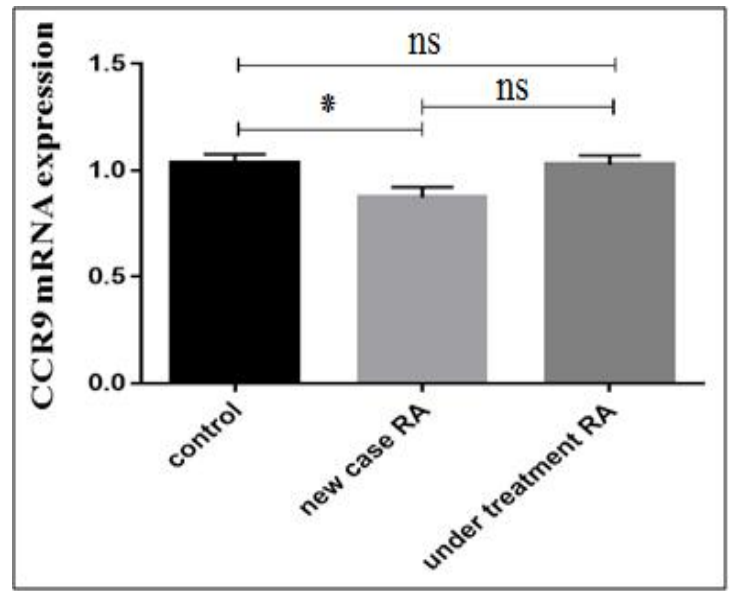

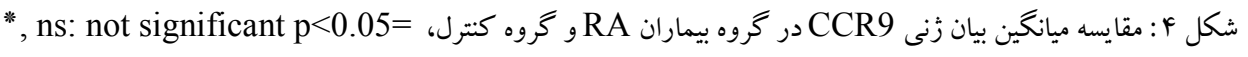

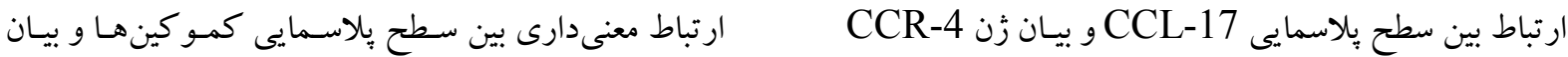

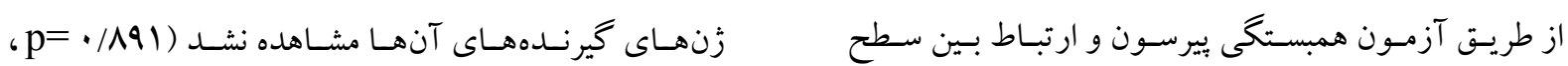

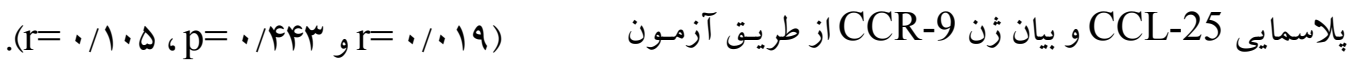

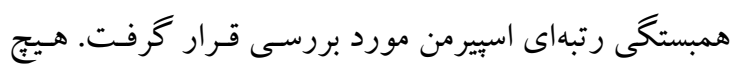

\begin{tabular}{|c|c|c|c|c|}
\hline \multicolumn{2}{|c|}{ بيماران آرتريت روماتوئيد } & \multirow[b]{2}{*}{ كنترل } & & \multirow[t]{2}{*}{ متغيرها } \\
\hline تحت درمان & تازه تشخيص & & & \\
\hline$r$. & $r$. & $r$. & & تعداد \\
\hline$\uparrow V / q \cdot \pm 1 / \Lambda \Delta$ & 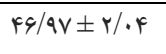 & $q V / q r \pm 1 / q 1$ & & ميانكين سن \\
\hline ( & (9مرد/ & ( & & جنسيت \\
\hline $1 .$. & . & . & MTX & \\
\hline $1 \ldots$ & . & . & HCQ & داروها (\%) \\
\hline $1 .$. & · & · & $\begin{array}{l}\text { PSL } \\
\text { Other }\end{array}$ & \\
\hline · & · & · & DMARDs & \\
\hline $1 \Delta / 1 \vee \pm 1 / V q^{* * *}$ & $r \cdot / v V \pm r / \Delta$ & - & & $\operatorname{ESR}(\mathrm{mm} / \mathrm{h})$ \\
\hline $1 / r V \pm \cdot / r f^{* * * *}$ & $9 / r V \pm \cdot / 90$ & - & & تعداد مفاصلدردناك \\
\hline$\cdot / v r \pm \cdot / / \kappa^{* * * * *}$ & $r / I V \pm \cdot / \uparrow$ & - & & تعداد مفاصل متورم \\
\hline$r / \mathcal{A r} \pm \cdot / / r^{* * * * * *}$ & $r / q \Delta \pm \cdot / / v$ & - & & DAS-28 \\
\hline
\end{tabular}

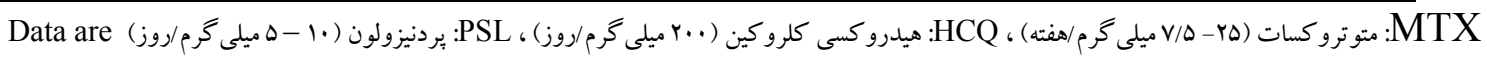

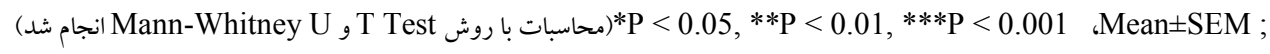




\begin{tabular}{|c|c|c|c|c|}
\hline \multirow[t]{2}{*}{$P$ value } & \multicolumn{2}{|c|}{ بيماران آرتريت روماتوئيد } & \multirow[b]{2}{*}{ كنترل } & \multirow[t]{2}{*}{ متغيرها } \\
\hline & تحت درمان & تازه تشخيص & & \\
\hline . / TFF & $a r / v V \pm F / V 1$ & $q . / I V \pm f / V V$ & $\Lambda r / 1 \cdot \pm \Delta / \uparrow \Delta$ & CCL17(a) \\
\hline 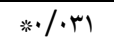 & $Q 9 / r \cdot \pm V / r r$ & $৭ ৭ / \wedge \vee \pm \Delta / \wedge r$ & $119 / \Gamma^{\prime} \pm \pm q / 49$ & CCL25(b) \\
\hline 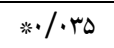 & $1 / 94 \pm \cdot / \cdot v$ & $1 / 4 r \pm \cdot / \cdot v q$ & $1 / 9 \mathrm{~V} \pm \cdot / .9 \mathrm{~V}$ & CCR4(a) \\
\hline$* \cdot / \cdot m$ & $1 / \cdot r \pm \cdot / \cdot \mu q$ & $\cdot / A V Y \pm \cdot / \cdot F q$ & $1 / r \pm \cdot / \cdot r \Delta$ & CCR9(a) \\
\hline
\end{tabular}

KrusKal Wallis آزمون (b) (b) (b) (a) (a)

جدول r: برايمرهاى اختصاصى جهت واكنش Real-time PCR

\begin{tabular}{|c|c|c|c|}
\hline زَن & يرايمر رفت & يرايمر بر گثت & اندازه \\
\hline GAPDH & GAAACCTGCCAAGTATGATG & AGGAAATGAGCTTGACAAAG & 188 \\
\hline CCR-4 & CTGCCCCCACTGTATTCCTTG & GAGCCGCTTGTATTTGAACAGG & 87 \\
\hline CCR-9 & GGTCATGGCTTGCTGCTATAC & CGGTCAGGACAGTGATGGT & 101 \\
\hline
\end{tabular}

جدول \& : برنامهى زمانبندى دستكاه Real-time PCR

\begin{tabular}{|c|c|c|c|}
\hline نوع برنامه & زمان & دما & تعداد سيكل \\
\hline Preincubation & با. & 199 درجه & 1 \\
\hline 2 Step & 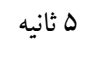 & ه9 درجه & \\
\hline Amplfication & r بانيه. & و لورجه. & f. \\
\hline \multirow{3}{*}{ Melting } & ه مثانيه & ه9 درجه & \multirow[t]{3}{*}{1} \\
\hline & 9 9 ثانيه & و & \\
\hline & ا انثيه & ه9 درجه & \\
\hline Cooling & r بانيه. & لهدرجه & 1 \\
\hline
\end{tabular}

هم در افراد سالم و هم بيماران مبتلا بـهـ آرتريست روماتوئيــ وابسته به فر ايندهاى ميـانجى گرى شــده توسط كمو كـاين بررسى ما نشان داد كه سطح بِلاسمايى كمو كاينهـا و بيـان هاست. نتايج اين مطالعه نشـان داد كـه بيـان زن CCR4 در زن گيرندههاى آنها در بيمـاران آرتريـت روماتوئيـد دجـار كروه بيماران تازه تشخيص داده شده نسبت به گرووه كنترل تغيير شده است. در واقع مهاجرت و لانهزئنى لكوسيتهـا 
دقيقى براى كاهش سلولهاىT CCR4 در خون محيطى

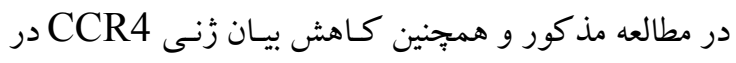

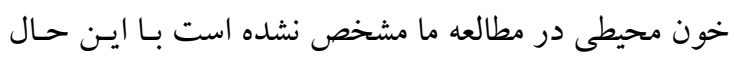
كاهش اين سلولها در خون محيطى يا كاهش اين بذ بذيرنسه

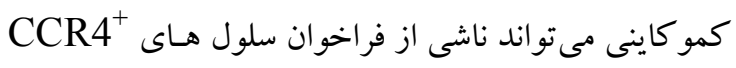
خون محيطى به مفاصل تحت تاثير ليگاند

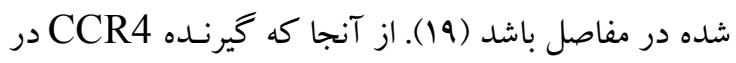

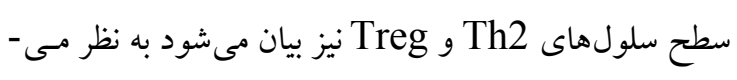
رسد كاهش سلولهاى CCR4 در خون محيطى بيماران

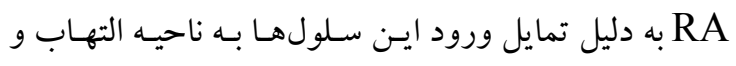

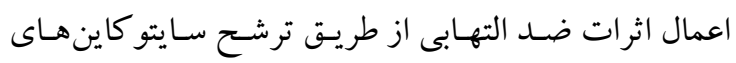

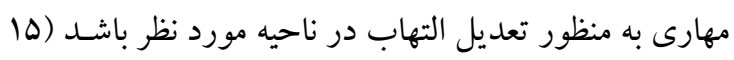

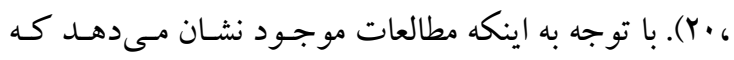

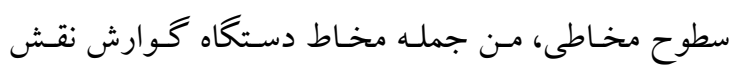

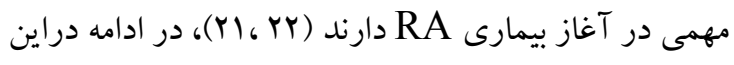

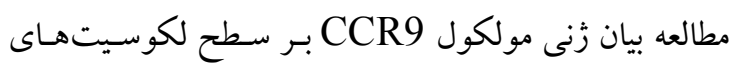
خون محيطى افرادى كه بيمارى آرتريت روماتوئيد در آنها

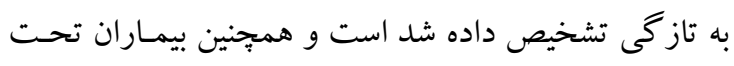

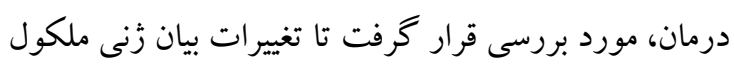

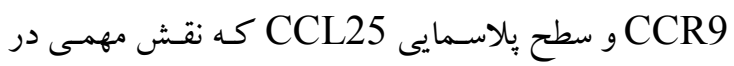

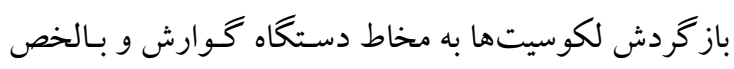
روده دارند بررسى شود. طبق يافتهاى اين طرح ميزان بيـان

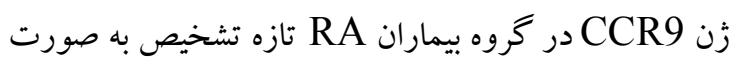
معنى دارى كمتر از گروه كنترل بـود و در گركروه بيماران

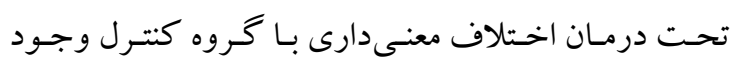

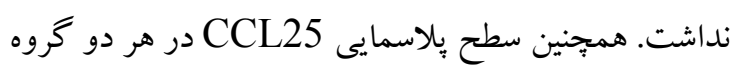
بيمار تازه تشخيص و تحت درمـان بـا اخـتلاف معنـادارى از

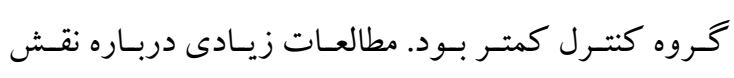
CCL25 ور باتوزنز بيمـارى RA CCR9 است. در مطالعهاى به افزايش بيـان CCR9 در مونوسيت-

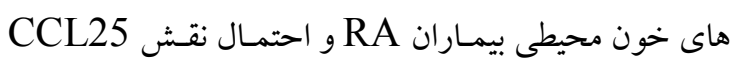

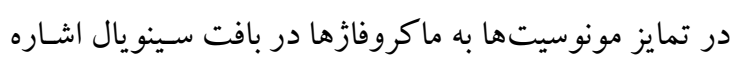
شده (YY). با اين حال يافتههاى ما مى تو اند مطرح كننده اين

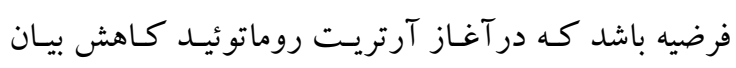

به طور معنى دار كاهش بيدا كرده است ولى ميزان بيان ايـن

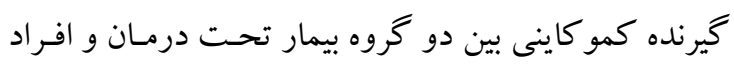

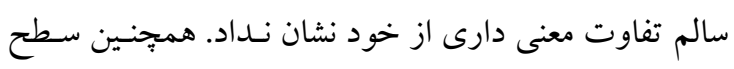

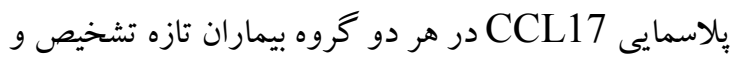

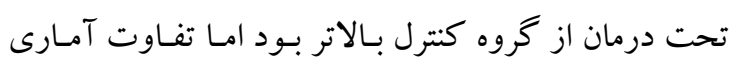
معنى دارى نداشت. مطالعـات مشـابه در ايـن زمينـه بـه نتـايج مختلفى دست يافتهاند. تعدادى از اين مطالعات، افزايش بيان

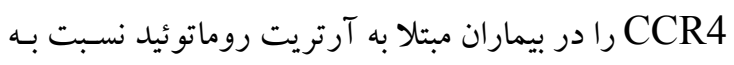
گروه كنترل گزارش كردهاند در حالى كه در برخى ديخر

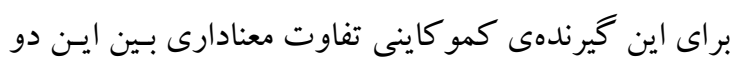

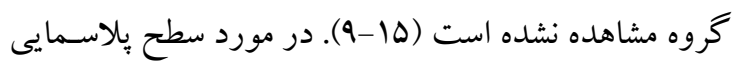
CCL17

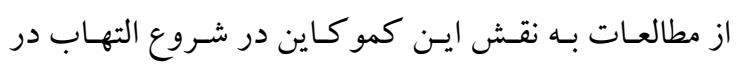
بيمارى آرتريت و ساير بيمارىهاى اتوايميون اشاره مى كنند در حالى كه در برخى ديخـر تفـاوت معنىدارى در سطح

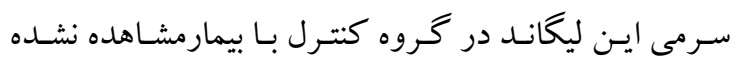

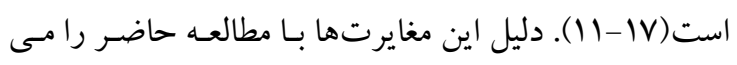

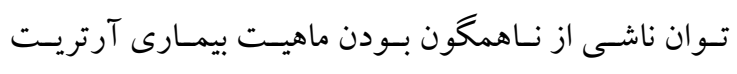

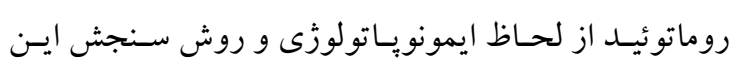
فاكتورها در زير گروههاى مختلف سلولى در سيستم ايمنى و

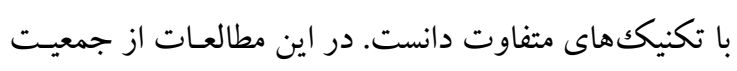

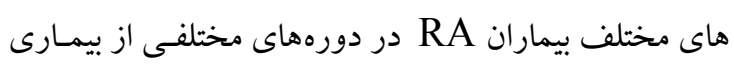

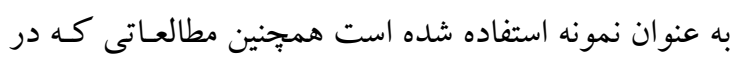

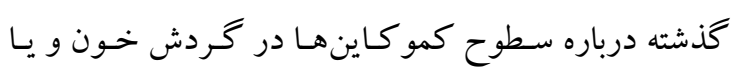

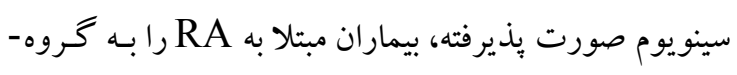

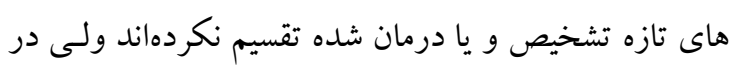

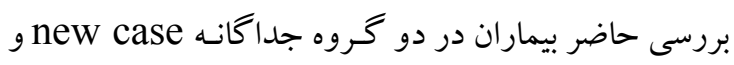
تحت درمان در مطالعه شركت داشتهاند. علاوه بر آن مطالعه درونه CCL17 و همكارانش نشان دادسطح بِاسمايى Pandya

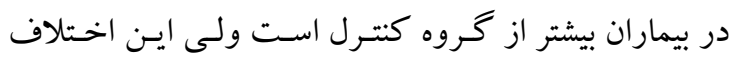
معنى دار نبود كه اين نتيجه همسو با يافتهاى ما مىباشد (1)

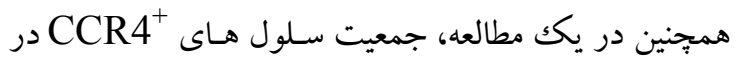

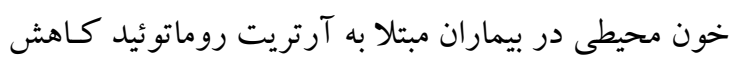
معنى دارى نسبت به گروه كنترل نشان داد. اخر جـهـ مكانيسم 
در لكوسيت هـاى خـون محيطى و كـاهش سطح

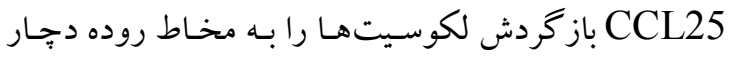

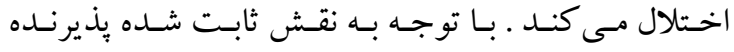

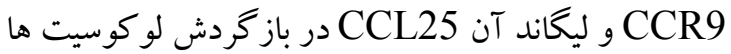
به مخاط روده و همجينين اهميت سيستم ايمنى ايـن ناحيـه از

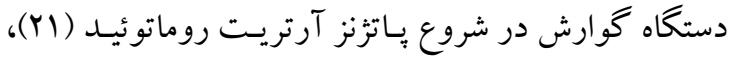
يافته ما در اين مطالعه اهميت ايمنى مخاطى دستكاه گَوارش

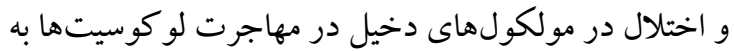
اين ناحيه را بيشتر در ياتوزنز آرتريت روماتوئيد مطرح مسى

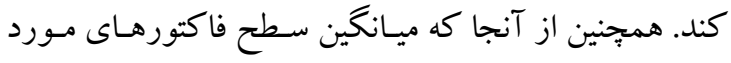

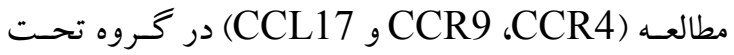
درمان در مقايسه با گروه افراد سالم اختـلاف معنى دارى را

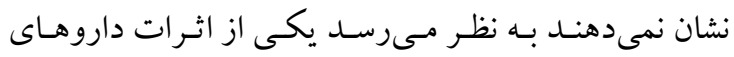

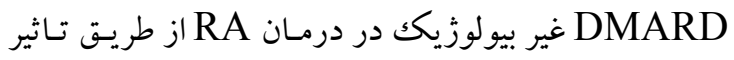

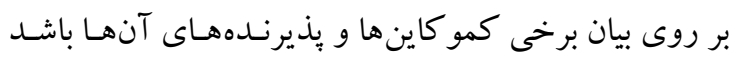

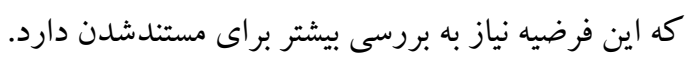
نتيجه كيرى

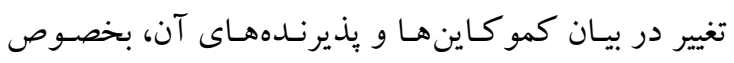

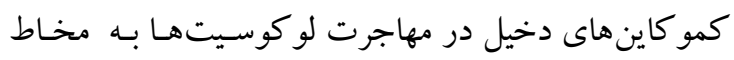

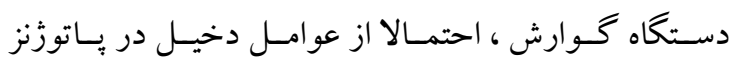
آرتريت روماتوئيد است. تشكر و قدردانى نـان

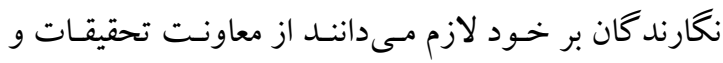

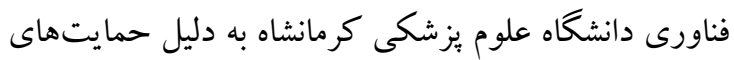

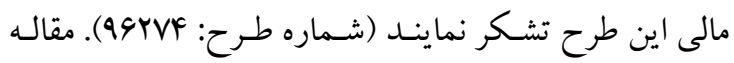

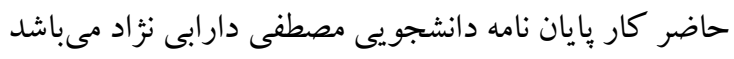

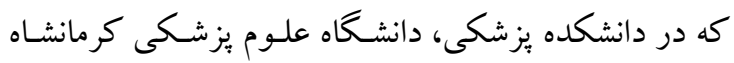

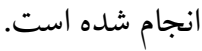


קسرابررسى هيران سطح يلاسمايِى...

\section{References}

1. Firestein GS. Evolving concepts of rheumatoid arthritis. Nature 2003;423:356.

2. Nalbandian A, Crispin J, Tsokos G. Interleukin-17 and systemic lupus erythematosus: current concepts. Clin Exp Immunol 2009;157:209-15.

3. Miossec P. Interleukin-17 in rheumatoid arthritis: if $\mathrm{T}$ cells were to contribute to inflammation and destruction through synergy. Arthritis Rheum 2003;48:594-601.

4. Shahrara S, Huang Q, Mandelin AM, Pope RM. TH-17 cells in rheumatoid arthritis. Arthritis Res Ther 2008;10:R93.

5. Moser B, Willimann K. Chemokines: role in inflammation and immune surveillance. Ann Rheum Dis 2004;63:ii84-ii9.

6. Mellado M, Martínez-Muñoz L, Cascio G, Lucas P, Pablos JL, Rodríguez-Frade JM. T cell migration in rheumatoid arthritis. Front Immunol 2015;6:384.

7. Campbell JJ, Butcher EC. Chemokines in tissue-specific and microenvironment-specific lymphocyte homing. Curr Opin Immunol 2000;12:336-41.

8. Wang C, Kang SG, HogenEsch H, Love PE, Kim CH. Retinoic acid determines the precise tissue tropism of inflammatory Th17 cells in the intestine. J Immunol 2010;184:5519-26.

9. Aletaha D, Neogi T, Silman AJ, Funovits J, Felson DT, Bingham III CO, et al. 2010 rheumatoid arthritis classification criteria: an American College of Rheumatology/European League Against Rheumatism collaborative initiative.Arthritis Rheum 2010;62:2569-81.

10. Pfaffl MW. A new mathematical model for relative quantification in real-time RT-PCR. Nucleic Acids Res 2001;29:e45-e.

11. Yang P, Kasai H, Zhao L, Xiao W, Tanabe F, Ito M. Increased CCR4 expression on circulating CD4+ $\mathrm{T}$ cells in ankylosing spondylitis, rheumatoid arthritis and systemic lupuserythematosus. Clin Exp Immunol 2004;138:342-7.

12. Yamada M, Yagita H, Inoue H, Takanashi T, Matsuda H, Munechika E, et al. Selective accumulation of CCR4+ T lymphocytes into renal tissue of patients with lupus nephritis. Arthritis Rheum 2002;46:735-40.

13. Ruth JH, Rottman JB, Katschke Jr KJ, Qin S, Wu L, LaRosa G, et al. Selective lymphocyte chemokine receptor expression in the rheumatoid joint. Arthritis Rheum 2001;44:2750-60.

14. Norii M, Yamamura M, Iwahashi M, Ueno A, Yamana J, Makino H. Selective recruitment of $\mathrm{CXCR} 3^{\wedge}+$ and $\mathrm{CCR} 5^{\wedge}+\mathrm{CD}^{\wedge}+\mathrm{T}$ cells into synovial tissue in patients with rheumatoid arthritis. Acta Med Okayama 2006;60:149-57.

15. LiN, Wei W, Yin F, Chen M, Ma TR, Wu Q, et al. The abnormal expression of CCR4 and CCR6 on Tregs in rheumatoid arthritis. Int J Clin Exp Med 2015;8:15043-53.

16. Moret FM, Hack CE, van der Wurff-Jacobs KM, de JagerW, Radstake TR, Lafeber FP, et al. Intra-articular CD1c-expressing myeloid dendritic cells from rheumatoid arthritis patients express a unique set of T cell-attracting chemokines and spontaneously induce Th1, Th17 and Th2 cell activity. Arthritis Res Ther 2013;15:R155.

17. Radstake TR, van der Voort R, ten Brummelhuis M, de Waal Malefijt M, Looman M, Figdor C, et al. Increased expression of CCL18, CCL19, and CCL17 by dendritic cells from patients with rheumatoid arthritis, and regulation byFc gamma receptors. Ann Rheum Dis 2005;64:359-67.

18. Pandya JM, Lundell A-C, Andersson K, Nordström I, Theander E, Rudin A. Blood chemokine profile in untreated early rheumatoid arthritis: CXCL10 as a disease activity marker. Arthritis Res Ther 2017;19:20. 


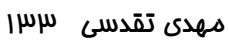

19. Suzuki N, Nakajima A, Yoshino S, Matsushima K, Yagita H, Okumura K. Selective accumulation of CCR5+ $\mathrm{T}$ lymphocytes into inflamed joints of rheumatoid arthritis.Int Immunol 1999;11:553-9.

20. Thompson SD, Luyrink LK, Graham TB, Tsoras M, Ryan M, Passo MH, et al. Chemokine receptor CCR4 on CD4+ T cells in juvenile rheumatoid arthritis synovial fluid defines a subset of cells with increased IL-4: IFN- $\gamma$ mRNA ratios. J Immunol 2001;161:6899906.

21. Demoruelle MK, Deane KD, Holers VM. When and where does inflammation begin in rheumatoid arthritis. Curr Opin Rheumatol 2014;26:64-71.

22. Schmutz C, Cartwright A, Williams H, Haworth O, Williams JH, Filer A, et al. Monocytes/macrophages express chemokine receptor CCR9 in rheumatoid arthritis and CCL25 stimulates their differentiation. Arthritis Res Ther 2010;12:R161. 